\title{
Identification the number of Mycobacterium tuberculosis based on sputum image using local linear estimator
}

\author{
Nur Chamidah ${ }^{1}$, Yolanda Swastika Yonani ${ }^{2}$, Elly Ana ${ }^{3}$, Budi Lestari ${ }^{4}$ \\ ${ }^{1,3}$ Department of Mathematics, Faculty of Science and Technology, Airlangga University, Indonesia \\ ${ }^{2}$ Study Program of Statistics, Faculty of Science and Technology, Airlangga University, Indonesia \\ ${ }^{4}$ Mathematics Department, Faculty of Mathematics and Natural Sciences, The University of Jember, Indonesia \\ ${ }^{1,3,4}$ Research Group of Statistical Modeling in Life Science, Faculty of Science and Technology, \\ Airlangga University, Indonesia
}

\section{Article Info}

Article history:

Received Oct 42019

Revised Dec 20, 2019

Accepted Apr 15, 2020

\section{Keywords:}

Classification accuracy

Local linear estimator

Mycobacterium tuberculosis

Nonparametric Poisson

regression

Sputum image

\begin{abstract}
Infectious disease caused by infection of Mycobacterium tuberculosis is called tuberculosis (TB). A common method in detecting TB is by identifying number of mycobacterium TB in sputum manually. Unfortunately, manually calculation by pathologists take a relatively long time. Previous researches on TB bacteria were still limited to detect the absence or presence of mycobacterium TB in images of sputum. This research aims are identifying number of mycobacterium TB and determining accuracy of classification TB severity by approaching nonparametric Poisson regression model and applying an estimator namely local linear. Steps include processing of image, reducing of dimension by applying partial least square and discrete wavelet transformation, and then identifying the number of mycobacterium TB by using the proposed model approach. In this research, we get deviance values of 28.410 for nonparametric and 93.029 for parametric approaches and the average of classification accuracy values for 4 iterations of $92.75 \%$ for nonparametric and $85.5 \%$ for parametric approaches. Thus, for identifying many of mycobacterium TB met in images of sputum and classifying of TB severity, the proposed identifying method gives higher accuracy and shorter time in identifying number of mycobacterium TB than parametric linear regression method.
\end{abstract}

This is an open access article under the CC BY-SA license.

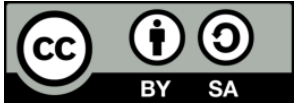

\section{Corresponding Author:}

Nur Chamidah,

Department of Mathematics,

Faculty of Science and Technology,

Airlangga University,

Jalan Mulyorejo Kampus C UNAIR, Surabaya 60115, Indonesia.

Email: nur-c@fst.unair.ac.id

\section{INTRODUCTION}

Mycobacterium tuberculosis can cause a direct infectious disease namely tuberculosis (TB). Identification of TB through microscopic observation (screening) using sputum smear samples has greatly helped prevent TB disease [1-7]. But, the process of identifying TB through microscopic screening requires a long time, high accuracy, and expert laboratory personnel. As a result of the long identification process that requires high accuracy, statistical modeling and software assistance are needed to identify TB disease from sputum samples of patients using processing of images. This process is one of processing digital images that is a discipline of study about digitally techniques to proceed images [8-10].

Studies related to the identification of TB from sputum images have been done by several researchers. Researchers [11-13] used meta analysis, [14] used self organizing map and [15] used 
the learning vector quantization (LVQ) method which gave accuracy of $91.33 \%$. The study by [16] used neural network methods that gave accuracy rate of 77.5\%, [17] used intelligence system, [18] used automatic scanning microscope, [19] used spatial domain filter, [20] studied by using artificial neural network (ANN) and Bayesian, [21, 22] used support vector mechine (SVM) method, [23] used deep learning and [24] used the gaussian fuzzy neural network (GFNN) method that gave accuracy rate of $91.38 \%$. Yet, the previous researchers detected the presence or absence of mycobacterium TB in sputum images of patients only. Thus, they have not identified how many TB bacteria which are in sputum images of patients. Also, they have not classified tuberculosis severity.

The previous detection of TB has been done manually which needs long time. In this research, we propose a statistical model approach that can shorten the time of counting TB bacteria. In statistical model approach, we can model the numbers of TB bacteria from patients of TB in regression models. There are parametric regression and nonparametric regression models. Estimation of the regression functions in these regression models have been studied by $[25,26]$. Nonparametric regression functions are only assumed to be smooth, i.e., continuous and differentiable functions so that they are very flexible to determine the regression functions [25]. There are several estimators for estimating nonparametric regression function. Local linear is one of them, that is, one of smoothing techniques in nonparametric regression and a specific case of local polynomial smoothing technique $[27,28]$.

In statistical modelling we can use the locally weighted maximum likelihood method for estimating function of regression at the observation points [28]. However, parameter estimation of Poisson regression by using the maximum likelihood method cannot be solved directly. It takes a Newton-Raphson iteration procedure. The Newton-Raphson method is one of the iterative methods used to solve equations that cannot be solved directly because they are not linear in parameters [28]. In addition, some statistical models have been used for modelling diseases data [29-35]. Therefore, in this research, we propose a statistical model approach called Poisson additive nonparametric regression model using local linear estimator to identify how many TB bacteria that are in sputum images of TB patients. Usually, dimension of sputum image is very large. Hence, we use discrete wavelet transformation (DWT) and partial least square (PLS) methods to reduce dimension of images.

\section{RESEARCH METHOD}

We use secondary data of 100 images of TB sputum that consist of 75 in-samples data and 25 out-samples data. The steps of research include processing of image, reducing of dimension, identifying the number of bacteria by using nonparametric and parametric regressions approaches, and classifying of tuberculosis severity.

\subsection{Processing of image}

We need this step to upgrade quality of image for exploring more information about TB bacteria contained by TB sputum based on its image in order to the next stages of image processing are easier. These stages are started by process of reading TB sputum image data file, process of gray-scaling, process of thresholding, process of histogram equalization, and process of resizing image. Figure 1 shows pictures of these stages. Next, results of resizing image process are replaced into a matrix where columns of matrix represent predictors and rows of matrix represent observations.

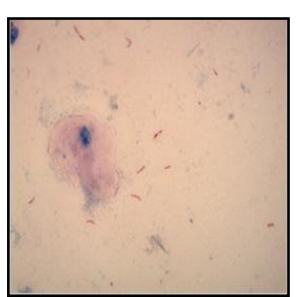

(a)

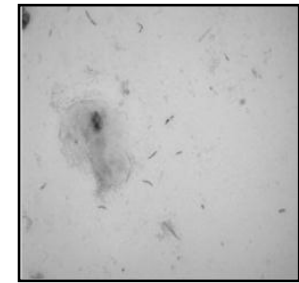

(b)

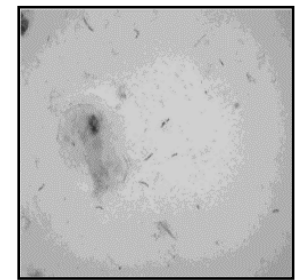

(c)

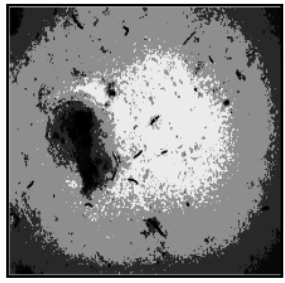

(d)

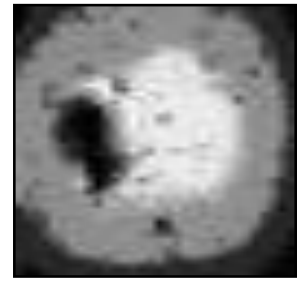

(e)

Figure 1. The stages of image processing (a) Image of TB sputum, (b) Grayscale, (c) Threshold, (d) Histogram equalization, (e) Resized image

\subsection{Dimension reduction using DWT and PLS}

Tuberculosis sputum image is obtained from ZNSM-IDB (Ziehl-Neelsen sputum smear microscopy image database) which can access by $14.139 .240 .55 / \mathrm{znsm}$. For each image, tuberculosis sputum image has 
a very large size. Because of this fact we meet difficulties in calculating data. Hence, we need reduce dimension to smaller dimension. In this research, to reduce dimension we use DWT method. This method gives result which closed to the origin variable and able to handle data with high dimension. However, this method still remains multicolinearity between variables in the model, because mathematically we cannot warrant that the correlation coefficients between these variables are relatively small. Therefore, we need PLS method to overcome this multicolinearity, because this method produces new mutually independent variables. The following steps are needed in reducing dimension:

a. Defining matrix $\mathbf{A}_{(n \times q)}$ for a sample size $n$ and $q=2^{M}$ for a positive integer $\mathrm{M}$;

b. Determining an orthogonal wavelet matrix $\mathrm{W}_{(q \times q)}$;

c. Determining wavelet coefficient matrix $\mathrm{D}$ that is transformation result of $\mathrm{W}$ in step $\mathrm{b}$;

d. Determining $\mathrm{m}(m<n)$ that follows $\mathrm{D}_{(n \times m)}^{*}=\mathrm{X}_{(n \times q)} \mathrm{W}_{(q \times m)}^{T}$ by substituting zero values into the ( $m+1$ )-th column to the $q$-th column;

e. Determining matrix $\mathrm{D}_{(n \times m)}^{*}$ that is a correlation matrix to check co-linearity;

f. Determining best number of components based on the percentage of variance and the value of root mean square error of prediction (RMSEP);

g. Determining the optimal number of latent vectors based on the RMSEP plot;

h. Calculating the optimal component X-score selected to determine the number of predictor variables after being reduced.

Based on steps from (a) to (h), we reduce 2048 predictor variables to 5 predictor variables.

\subsection{Estimate the number of bacteria using nonparametric and parametric regressions}

We conduct the following steps to identify the data:

- Testing the number of Mycobacterium tuberculosis data (Y) with Poisson distribution;

- Determining optimal bandwidths for every predictor using cross validation (CV) criterion;

- Estimating regression function based on obtained optimal bandwidth by using locally weighted maximum likelihood and Newton-Raphson iteration methods;

- Providing plots of observations data (Y) and estimation results $(\boldsymbol{\mu})$;

- Testing the suitability of the estimated model by using statistics testing of deviance;

- Analyzing and giving interpretation to the estimated model that has been obtained.

\section{RESULTS AND DISCUSSION}

Based on 100 observations, we have 2048 predictor variables that is reduced to 5 predictor variables through image processing by using DWT and PLS methods. These reduced predictors will be modeled for estimating the number of Mycobacterium tuberculosis in the sputum image. Firstly, by using parametric Poisson regression model approach we estimate the number of Mycobacterium tuberculosis. To reach it, we estimate parameters of model, do simultaneously and individually significant testing, estimate the number of bacteria, and calculate accuracy in each observation. Values of estimation are given in Table 1.

Table 1. Values of estimation for parametric Poisson regression

\begin{tabular}{lllll}
\hline Predictor & Coefficient & SE-coefficient. & $\mathrm{Z}$ & $\mathrm{P}$ \\
\hline Intercept & 2.607 & 0.032 & 80.679 & 0.000 \\
$\mathrm{X} 1$ & 0.044 & 0.033 & 1.350 & 0.177 \\
$\mathrm{X} 2$ & 2.526 & 0.402 & 6.272 & 0.000 \\
$\mathrm{X} 3$ & 2.294 & 0.533 & 4.299 & 0.000 \\
$\mathrm{X} 4$ & 1.633 & 0.541 & 3.017 & 0.002 \\
$\mathrm{X} 5$ & 0.963 & 0.453 & 2.125 & 0.033 \\
\hline
\end{tabular}

In this research, for each observation we obtain the estimated value $\hat{\mu}_{i}$ as follows:

$$
\hat{\mu}_{i}=e^{\left(2.607+0.044 X_{1}+2.526 X_{2}+2.294 X_{3}+1.633 X_{4}+0.963 X_{5}\right)}
$$

The second step is identifying the number Mycobacterium tuberculosis by using local linear estimator of nonparametric Poisson regression model. To obtain the estimated regression function, it is 
necessary to determine the optimal bandwidth $(h)$ using $\mathrm{CV}$ criterion. Plots of CV versus bandwidth values for every predictor variable are given in Figures 2-6 and the optimal bandwidths and minimum CV values for every predictor variable are given in Tables 2 .

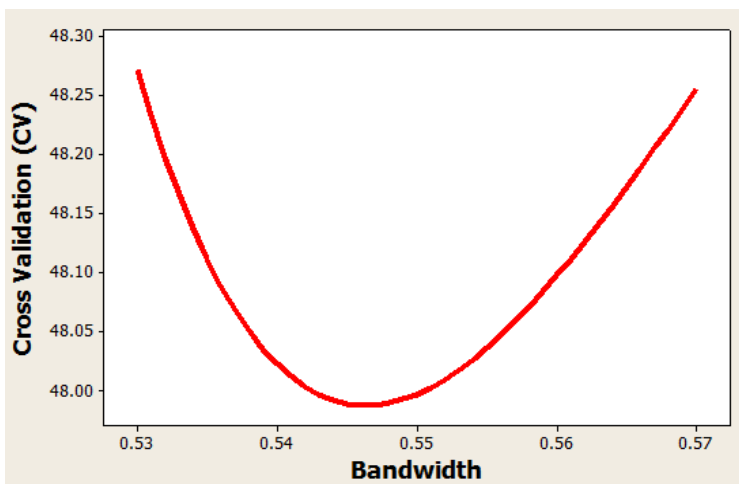

Figure 2. Plot of cross validation values of bandwidths for predictor 1 (X1)

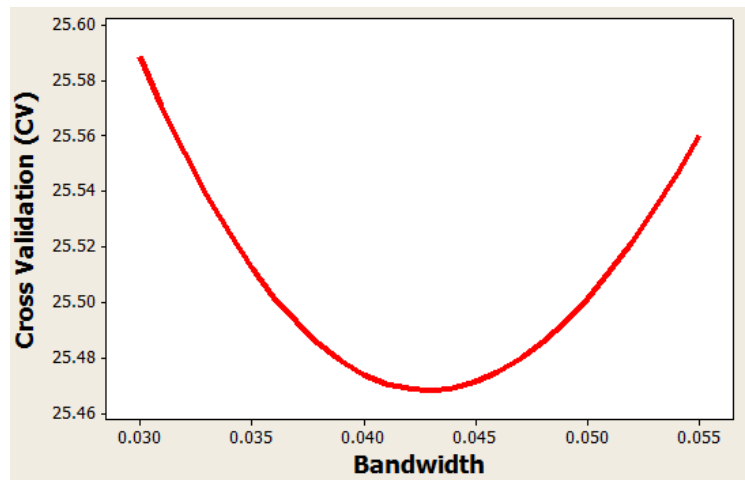

Figure 4. Plot cross validation values of bandwidths for predictor $3(\mathrm{X} 3)$

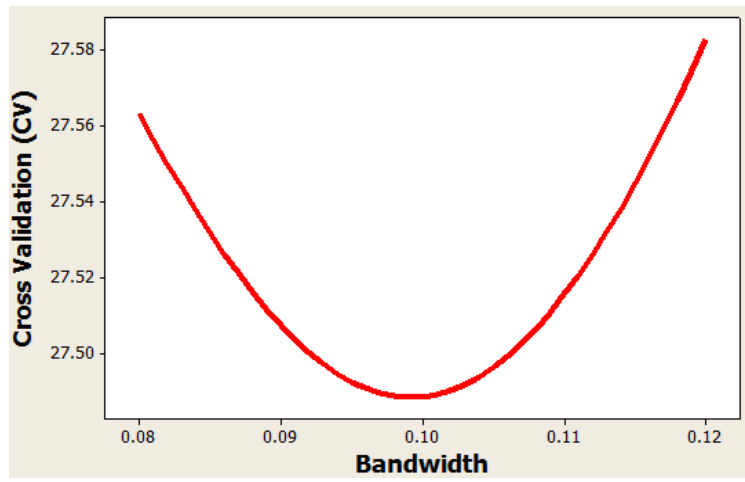

Figure 6. Plot of cross validation values of bandwidths for predictor 5 (X5)

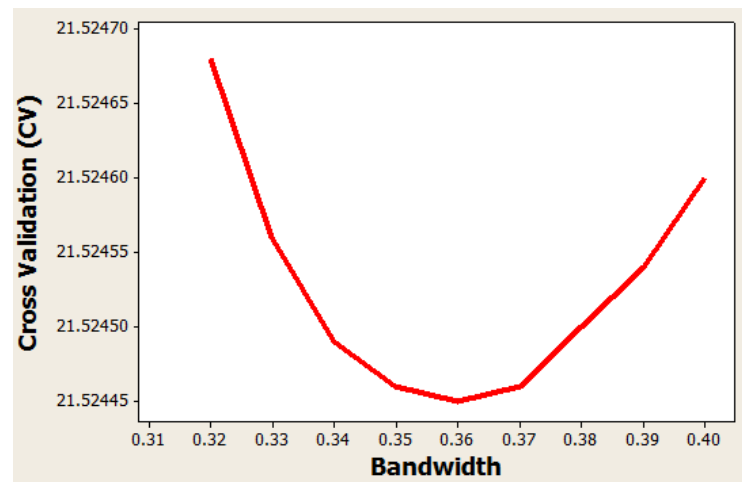

Figure 3. Plot of cross validation values of bandwidths for predictor 2 (X2)

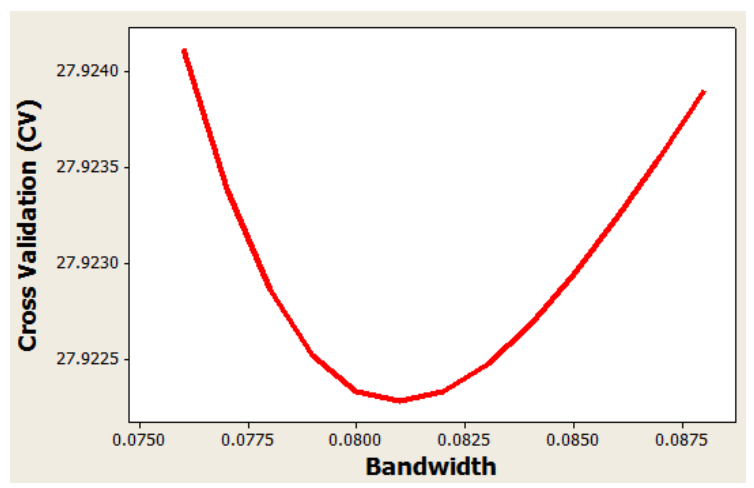

Figure 5. Plot of cross validation values of bandwidths for predictor $4(\mathrm{X} 4)$

Table 2. The optimal bandwidths and minimum CV values for every predictor variable

\begin{tabular}{lll}
\hline Predictor & Optimal bandwidth $(h)$ & Minimum CV value \\
\hline $\mathrm{X}_{1}$ & 0.546 & 47.98752 \\
$\mathrm{X}_{2}$ & 0.36 & 21.52445 \\
$\mathrm{X}_{3}$ & 0.043 & 25.46812 \\
$\mathrm{X}_{4}$ & 0.081 & 27.92228 \\
$\mathrm{X}_{5}$ & 0.099 & 27.48833 \\
\hline
\end{tabular}

Then, we use values given in Table 2 to get estimated model for every observation, that is $\hat{\mu}_{i}$. For example, on the $26^{\text {th }}$ observation we estimate $\hat{\mu}_{26}$ model as follows: 


$$
\begin{gathered}
\hat{\mu}_{26}=\exp \left\{2.486-0.264\left(X_{1}-0.347\right)+1.960\left(X_{2}-0.140\right)+3.331\left(X_{3}+0.143\right)+\right. \\
\left.3.224\left(X_{4}+0.033\right)+1.345\left(X_{5}-0.154\right)\right\}
\end{gathered}
$$

where $X_{1} \in\left(X_{1}-0.546, X_{1}+0.546\right) ; X_{2} \in\left(X_{2}-0.36, X_{2}+0.36\right) ; X_{3} \in\left(X_{3}-0.043, X_{3}+0.043\right)$

$$
X_{4} \in\left(X_{4}-0.081, X_{4}+0.081\right) ; X_{5} \in\left(X_{5}-0.099, X_{2}+0.099\right) \text {. }
$$

Estimation plots of the number of Mycobacterium tuberculosis by using parametric Poisson linear regression and nonparametric Poisson regressions based on local linear estimator for 75 observations are given together in Figure 7. Next, we compare the estimation results between parametric Poisson linear regression and nonparametric Poisson regression approaches using local linear estimator based on goodness of fit criterion that is minimum deviance value. These results are shown in Table 3.

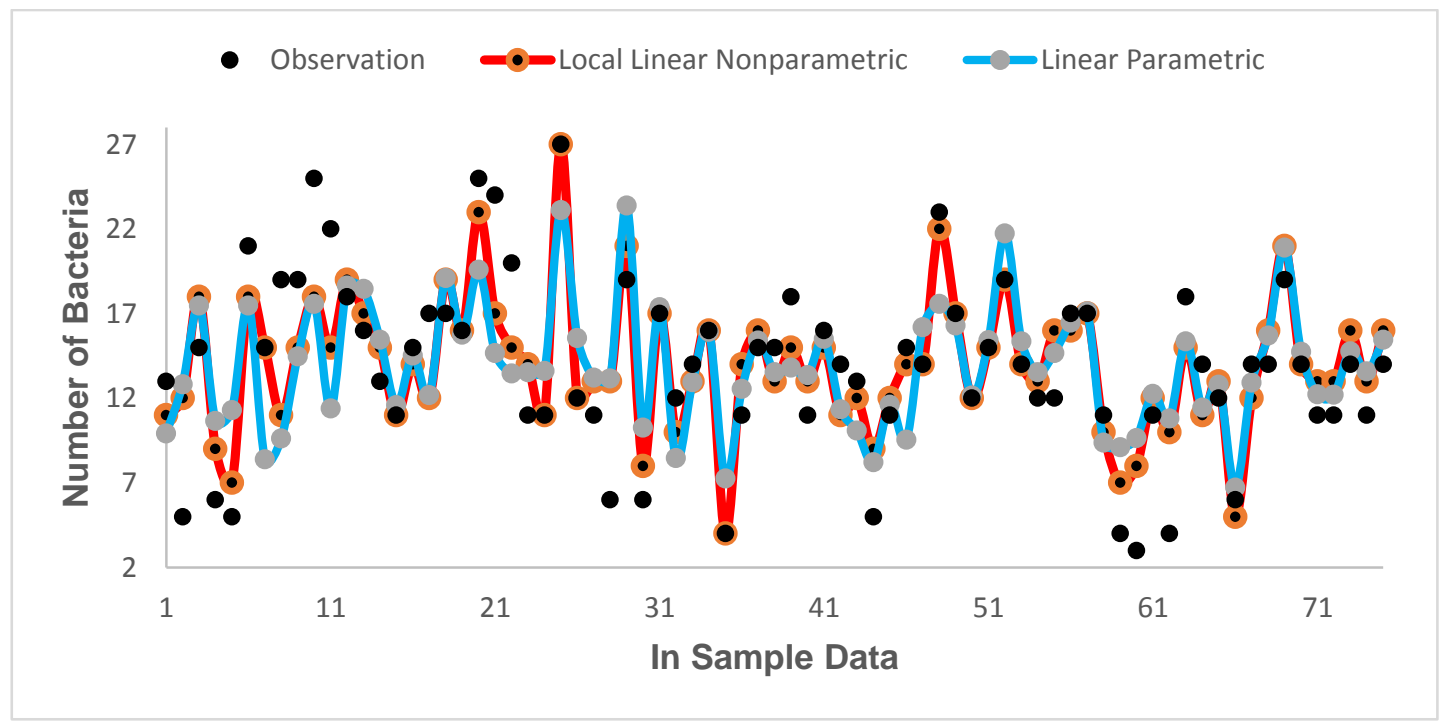

Figure 7. Plots of estimation results using parametric Poisson linear regression and nonparametric Poisson regressions approaches

Table 3. Deviance values of parametric and nonparametric regressions approaches

\begin{tabular}{ll}
\hline Model & Deviance \\
\hline Parametric Poisson linear regression & 93.029 \\
Nonparametric Poisson local linear regression & 28.410 \\
\hline
\end{tabular}

Table 3 shows that deviance value of nonparametric Poisson local linear regression model approach is less than that of parametric Poisson linear regression model approach. It points out that in this case, use of nonparametric Poisson local linear regression model is more suitable to model and analyze the data than that of parametric Poisson linear regression. This fact is also supported by the deviance testing results of the Poisson regression with linear parametric model approach and the Poisson regression with nonparametric model approach by using local linear estimator for in-sample data. The deviance testing result of the Poisson regression by using linear parametric model approach shows that the deviance value of 93.029 is greater than Chi-square $\chi_{(70 ; 0.05)}^{2}$ value of 90.5312 with significance level 5\%. It means that statistically, the Poisson regression by using linear parametric model approach is not suitable to model and analyze the data. In contrary, the deviance testing result of nonparametric Poisson regression model approach by using local linear estimator shows that the deviance value of 28.410 is less than Chi-square $\chi_{(70 ; 0.05)}^{2}$ value of 90.5312 with significance level 5\%. Therefore, the nonparametric Poisson local linear regression model approach is more appropriate to model and analyze the data than the Poisson linear parametric regression model approach.

Furthermore, after identifying the number of Mycobacterium tuberculosis we also can classify tuberculosis severity based on the IUATLD scale. The result of the accuracy of tuberculosis severity 
classification is $95 \%$. This result indicates that the obtained model is valid for classifying the severity of tuberculosis. The classification accuracy values of parametric Poisson linear regression and nonparametric Poisson local linear regression models approaches for 4 iterations are shown in Table 4 . Table 4 shows that in four iterations, average of classification accuracy values of nonparametric Poisson regression model approach by using local linear estimator is $92.75 \%$, and average of classification accuracy values of parametric Poisson linear regression model approach is $85.5 \%$. It means that the average of classification accuracy of suffering level of tuberculosis by using nonparametric Poisson regression model approach based on local linear estimator is better than that by using parametric Poisson linear regression model approach.

Table 4. Classification accuracy values of parametric Poisson linear regression and nonparametric Poisson local linear regression models for four iterations

\begin{tabular}{lll}
\hline Iteration & $\begin{array}{l}\text { Classification accuracy } \\
\text { Nonparametric regression model }\end{array}$ & Parametric regression model \\
\hline 1 & $95 \%$ & $85 \%$ \\
2 & $91 \%$ & $86 \%$ \\
3 & $92 \%$ & $87 \%$ \\
4 & $93 \%$ & $84 \%$ \\
Average & $\mathbf{9 2 . 7 5 \%}$ & $\mathbf{8 5 . 5 \%}$ \\
\hline
\end{tabular}

\section{CONCLUSION}

Based on average of classification accuracy values and deviance value, for identifying the number of Mycobacterium tuberculosis, the Poisson regression by using nonparametric Poisson regression model approach based on local linear estimator is better than parametric Poisson linear regression model approach. Thus, the proposed identifying method gives higher accuracy and shorter time in identifying number of mycobacterium TB than parametric Poisson linear regression method.

\section{REFERENCES}

[1] J. L. Davis, A. Cattamanchi, L. E. Cuevas, P. C. Hopewell, and K. R. Steingart, "Diagnostic accuracy of same-day microscopy versus standard microscopy for pulmonary tuberculosis: A systematic review and meta-analysis," The Lancet Infect. Dis., vol. 13, no. 2, pp.147-154, 2013.

[2] M. I. Shah, S. Mishra, M. Sarkar, and S. K. Sudarshan, "Automatic detection and classification of tuberculosis bacilli from camera-enabled smartphone microscopic images," 2016 Fourth International Conference on Parallel, Distributed and Grid Computing (PDGC), pp. 287-290, 2016.

[3] T. J. Chandra, R. Selvaraj, and Y. V. Sharma, "Same-day sputum smear microscopy for the diagnosis of pulmonary tuberculosis: Direct vs. concentrated smear," The Int. J. Tuberc. Lung. Dis., vol. 20, no. 2, pp. 247-251, 2016.

[4] E. W. Chang, A. L. Page, and M. Bonnet, "Light-emitting diode fluorescence microscopy for tuberculosis diagnosis: A meta-analysis," Eur. Respir. J., vol. 47, no. 3, pp. 929-937, 2016.

[5] M. I. Shah, S. Mishra, V. K. Yadav, A. Chauhan, M. Sarkar, S. K. Sharma, and C. Rout, "Ziehl-Neelsen sputum smear microscopy image database: A resource to facilitate automated bacilli detection for tuberculosis diagnosis," Journal of Medical Imaging, vol. 4, no. 2, 2017.

[6] Y. P. López, C. F. F. Costa Filho, L. M. R. Aguilera, and M. G. F. Costa, "Automatic classification of light field smear microscopy patches using convolutional neural networks for identifying Mycobacterium tuberculosis," 2017 CHILEAN Conference on Electrical, Electronics Engineering, Information and Communication Technologies (CHILECON), pp. 1-5, 2017.

[7] O. A. Osibote, R. Dendere, S. Krishnan, and T. S. Douglas, "Automated focusing in bright-field microscopy for tuberculosis detection," Journal of Microscopy, vol. 240, no. 2, pp. 155-163, 2010.

[8] F. Mokhtar, R. Ngadiran, T. Basheer, and A. N. A. Rahim, "Analysis of wavelet-based full reference image quality assessment algorithm," Bulletin of Electrical Engineering and Informatics, vol. 8, no. 2, pp. 527-532, 2019.

[9] W. AlQaisi, M. AlTarawneh, Z. A. Alqadi, and A. A. Sharadqah, "Analysis of color image features extraction using texture methods," TELKOMNIKA Telecommunication, Computing, Electronics and Control, vol. 17, no. 3, pp. 1220-1225, 2019.

[10] N. E. A. Khalid, M. F. Ismail, M. A. AB. Manaf, A. F. A. Fadzil, and S. Ibrahim, "MRI brain tumor segmentation: A forthright image processing approach," Bulletin of Electrical Engineering and Informatics, vol. 9, no. 3, pp. 1024-1031, 2020.

[11] E. Noykhovich, S. Mookherji, and A. Roess, "The risk of tuberculosis among populations living in slum settings: A systematic review and meta-analysis," J. Urban Health, vol. 96, no. 2, pp. 262-275, 2019.

[12] S. Datta, L. Shah, R. H. Gilman, and C.A. Evans, "Comparison of sputum collection methods for tuberculosis diagnosis: A systematic review and pairwise and network meta-analysis," The Lancet Global Health, vol. 5, no. 8, pp. 760-771, 2017. 
[13] R. Sathiyamoorthy, M. Kalaivani, P. Aggarwal, and S. K. Gupta, "Prevalence of pulmonary tuberculosis in India: A systematic review and meta-analysis," Lung India: Official Organ of Indian Chest Society, vol. 37, no. 1, pp. 45-52, 2020.

[14] R. Rulaningtyas, A. B. Suksmono, T. L. R. Mengko, and P. Saptawati, "Colour segmentation of multi variants tuberculosis sputum images using self organizing map," Journal of Physics: Conference Series, vol. 853, pp. 1-6, 2017.

[15] E. Purwanti and P. Widiyanti, "Using learning vector quantization method for automated identification of Mycobacterium tuberculosis," Indonesian J. of Tropical and Infectious Disease, vol. 3, no. 1, pp. 26-29, 2012.

[16] F. C. S. Arisgraha, P. Widiyanti, and R. Apsari, "Digital detection system design of Mycobacterium tuberculosis through extraction of sputum image using neural network method," Indonesian Journal of Tropical and Infectious Disease, vol. 3, no. 1, pp. 35-38, 2012.

[17] R. Rulaningtyas, A. B. Suksmono, T. L. R. Mengko, P. Saptawati, and Winarno, "The improvement of automatic scanning microscope based on intelligent systems to identify Mycobacterium tuberculosis," International Journal of Ecology \& Development, vol. 29, no. 3, pp. 14-31, 2014.

[18] R. Rulaningtyas, A. B. Suksmono, T. L. R. Mengko, and P. Saptawati, "Identification of Mycobacterium tuberculosis in sputum smear slide using automatic scanning microscope," AIP Conference Proceedings, vol. 1656, no. $1,2015$.

[19] A. Rachmad, N. Chamidah, and R. Rulaningtyas, "Image enhancement sputum containing Mycobacterium tuberculosis using a spatial domain filter," IOP Conf. Series: Materials Science and Engineering, vol. 546, no. 5, pp. 1-7, 2019.

[20] F. Taher, N. Werghi, and H. Al-Ahmad, "Bayesian classification and artificial neural network methods for lung cancer early diagnosis," 2012 19th IEEE International Conference on Electronics, Circuits, and Systems (ICECS 2012), pp. 773-776, 2012.

[21] K. Adi, R. Gernowo, A. Sugiharto, K. S. Firdausi, A. Pamungkas, and A. B. Putranto, "Tuberculosis (TB) identification in the Ziehl-Neelsen sputum sample in NTSC channel and support vector machine (SVM) classification," International Journal of Innovative Research in Science, Engineering and Technology, vol. 2, no. 9, pp. 5030-5035, 2013.

[22] M. El-Melegy, D. Mohamed, T. ElMelegy, and M. Abdelrahman, "Identification of tuberculosis bacilli in ZNstained sputum smear images: A deep learning approach," 2019 IEEE/CVF Conference on Computer Vision and Pattern Recognition Workshops (CVPRW), pp. 1131-1137, 2019.

[23] K. S. Mithra and W. R. S. Emmanuel, "GFNN: Gaussian-fuzzy-neural network for diagnosis of tuberculosis using sputum smear microscopic images," Journal of King Saud University-Computer and Information Sciences, 2018.

[24] D. Aydin and E. Yilmaz, "Modified spline regression based on randomly right-censored data: A comparative study," Communications in Statistics-Simulation and Computation, vol. 47, no. 9, pp. 2587-2611, 2018.

[25] B. Lestari, Fatmawati, and I. N. Budiantara, "Spline estimator and its asymptotic properties in multiresponse nonparametric regression model," Songklanakarin Journal of Science and Technology (SJST), vol. 42, no. 3, pp. 533-548, 2020.

[26] B. Lestari, Fatmawati, I. N. Budiantara, and N. Chamidah, "Smoothing parameter selection method for multiresponse nonparametric regression model using smoothing spline and kernel estimators approaches," Journal of Physics: Conference Series, vol. 1397, pp. 1-8, 2019.

[27] N. Chamidah and B. Lestari, "Estimation of covariance matrix using multiresponse local polynomial estimator for designing children growth charts: A theoretically discussion," Journal of Physics: Conference Series, vol. 1397, pp. 1-8, 2019.

[28] N. Chamidah, K. H. Gusti, E. Tjahjono, and B. Lestari, "Improving of classification accuracy of cyst and tumor using local polynomial estimator," TELKOMNIKA Telecommunication, Computing, Electronics and Control, vol. 17, no. 3, pp. 1492-1500, 2019.

[29] J. A. Santos and M. M. Neves, "A local maximum likelihood estimator for poisson regression," Metrika, vol. 68, pp. 257-270, 2008.

[30] Y. X. Sun, L. Zhu, Z. H. Lu, and Z. W. Jia, "Notification rate of tuberculosis among migrants in China 2005-2014: A systematic review and meta-analysis," Chinese Medical Journal, vol. 129, no. 15, pp.1856-1860, 2016

[31] A. E. Anwar and N. Chamidah, "Glaucoma identification on fundus retinal images using statistical modelling approach,” IOP Conf. Series: Materials Science and Engineering, vol. 546, no. 5, pp. 1-8, 2019.

[32] A. Puspitawati and N. Chamidah, "Choroidal neovascularisation classification on fundus retinal images using local linear estimator," IOP Conf. Series: Materials Science and Engineering, vol. 546, no. 5, pp. 1-6, 2019.

[33] N. Rizka and N. Chamidah, "Lung tumor classification on human chest X-Ray using statistical modelling approach," IOP Conf. Series: Materials Science and Engineering, vol. 546, no. 5, pp. 1-9, 2019.

[34] R. N. Rohmah, B. Handaga, Nurokhim, and I. Soesanti, "A statistical approach on pulmonary tuberculosis detection system based on X-Ray image," TELKOMNIKA Telecommunication, Computing, Electronics and Control, vol. 17, no. 3, pp. 1474-1482, 2019.

[35] Y. Wang, W. Guo, and M. B. Brown, "Spline smoothing for bivariate data with applications to association between hormones," Statistica Sinica, vol. 10, no. 2, pp. 377-397, 2000. 


\section{BIOGRAPHIES OF AUTHORS}
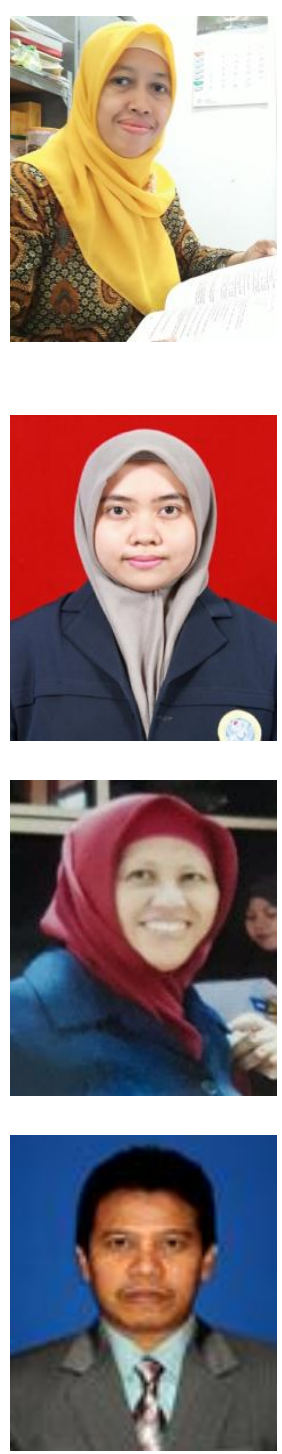

Nur Chamidah was born in Surabaya, East Java, Indonesia on 2 June 1972. She received bachelor (S.Si.) degree in Mathematics from Airlangga University, Surabaya, Indonesia in 1997, Masters (M.Si.) degree in Statistics from Sepuluh Nopember Institute of Technology, Surabaya, Indonesia in 2002, and Doctorate (Dr.) degree in Statistics from Sepuluh Nopember Institute of Technology, Surabaya, Indonesia in 2014. She works for as a lecturer at the study program of Statistics, Department of Mathematics, Faculty of Science and Technology, Airlangga University, Surabaya, Indonesia, and a headmaster of Research Group of Statistical Modeling in Life Science, Faculty of Science and Technology, Airlangga University, Surabaya, Indonesia. Her research interests are Statistical Modeling in Life Science, Spatial Model, and Nonparametric and Semiparametric regressions models.

Yolanda Swastika Yonani is a graduate student of Statistics Study Program, Department of Mathematics, Faculty of Science and Technology, Airlangga University, Surabaya, Indonesia. Her research interests are Statistical Modeling in Life Science and Nonparametric regressions models.

Elly Ana received bachelor (Ir.) and Masters (M.Si.) degrees in Statistics from Agricultural Institute of Bogor, Indonesia. She is currently a lecturer at study program of Statistics, Department of Mathematics, Faculty of Science and Technology, Airlangga University, Surabaya, Indonesia, and a member of Research Group of Statistical Modeling in Life Science, Faculty of Science and Technology, Airlangga University, Surabaya, Indonesia. Her research interests are Statistical Modeling in Social Science, and Sampling Techniques.

Budi Lestari was born in Tulungagung, East Java, Indonesia on 25 October 1963. He received bachelor (Drs.) degree in Mathematics from Gadjah Mada University, Yogyakarta, Indonesia in 1990, Postgraduate Diploma (PG.Dip.Sc.) degree in Statistics from La Trobe University, Melbourne, Australia in 1999, Masters (M.Si.) degree in Statistics from Sepuluh Nopember Institute of Technology, Surabaya, Indonesia in 2003, and Doctorate (Dr.) degree in Mathematics and Natural Sciences from Airlanga University, Surabaya, Indonesia in 2019. Currently, he is a member of Research Group of Statistical Modeling in Life Science, Faculty of Science and Technology, Airlangga University, Surabaya, Indonesia. His research interests are Mathematical Statistics, Nonparametric and Semiparametric regressions models 